\title{
What is the difference in pedicle morphology of the fifth lumbar vertebra between isthmic and degenerative L5-S1 spondylolisthesis? An anatomic study of 328 patients via multi-slice spiral computed tomography
}

\author{
Chao Tang ( $\square$ tangchao199108@163.com ) \\ Ye Hui Liao \\ The Affiliated Hospital of Southwest Medical University \\ Qiang Tang \\ The Affiliated Hospital of Southwest Medical University \\ Fei Ma \\ The Affiliated Hospital of Southwest Medical University \\ Qing Wang \\ The Affiliated Hospital of Southwest Medical University \\ DeJun Zhong ( $\nabla$ zdj_1974@163.com) \\ The Affiliated Hospital of Southwest Medical University
}

The Affiliated Hospital of Southwest Medical University https://orcid.org/0000-0002-9352-6567

\section{Research Article}

Keywords: pedicle morphology, isthmic spondylolisthesis, degenerative spondylolisthesis, computed tomography

Posted Date: June 28th, 2021

DOI: https://doi.org/10.21203/rs.3.rs-277343/v1

License: @ (i) This work is licensed under a Creative Commons Attribution 4.0 International License. Read Full License 


\section{Abstract \\ Purpose}

The purpose of this study was to investigate and determine whether there are differences in L5 pedicles morphology between isthmic and degenerative L5-S1 spondylolisthesis.

\section{Methods}

One hundred and nineteen patients with isthmic spondylolisthesis and 45 patients with degenerative spondylolisthesis at L5-S1 were enrolled in the IS group and DS group, respectively, and 164 lumbar disc herniation patients without spondylolysis or spondylolisthesis were classified into the normal (NL) group. A series of pedicle parameters of the fifth lumbar vertebra, including pedicle length (PL), pedicle width (PW), pedicle screw trajectory length (PSTL), pedicle height (PH), and the pedicle camber angle (PCA) were measured using multi-slice spiral computed tomography (MSCT). The slip distance of the L5 vertebra was measured on radiography, and the percentage of slip was also recorded.

\section{Results}

The pedicles of the fifth lumbar vertebra were shorter and wider, and the PCA was larger in the IS group compared to the DS group and NL group. On the contrary, the pedicles in the DS group were elongated and thinner, and the PCA was smaller. The pedicle parameters of PL were significantly positively correlated with the percentage of slip in the DS group, but PW and PCA were negatively correlated with the percentage of slip. There was no correlation between the percentage of slip and L5 pedicle parameters in the IS group.

\section{Conclusions}

The L5 pedicles morphology in L5-S1 isthmic spondylolisthesis shows abduction, shortness, and width, while that in the degenerative spondylolisthesis shows adduction, lengthening, and thinning compared with the normal populations. The morphology changes may be the result of pedicle stress remodeling in the development of spondylolisthesis, which should be taken into consideration when placing at the insertion of pedicle screws.

\section{Introduction}

Spondylolisthesis can be divided into the following five types according to the Wiltse-Newman classification system in 1976: dysplastic, isthmic, degenerative, traumatic, and pathologic [1]. When patients become symptomatic and conservative management fails, surgical correction with posterior decompression and fusion using pedicle screw fixation is performed [2]. The pedicle anatomy in patients with spondylolisthesis varies greatly from those without spondylolysis or spondylolisthesis, and care must be taken when inserting pedicle screws $[3,4]$.

Previous literary works have shown that there are different morphological changes in the sliding vertebral body and its pedicle in lumbar spondylolisthesis due to different pathogenesis and causes [3,5-8]. To the best of our knowledge, no study has discussed the anatomic changes and difference in the slip vertebra and its pedicle between isthmic and degenerative spondylolisthesis to date. Therefore, the purpose of this study was to 1) measure the L5 pedicle parameters in patients between isthmic and degenerative spondylolisthesis at L5-S1 on multi-slice spiral computed tomography (MSCT), 2) analyze the morphological features and differences in the pedicle between isthmic and degenerative spondylolisthesis, and 3) clarify the relationship between the forward percentage of slip and the pedicle parameters in spondylolisthesis.

\section{Materials And Methods}

We performed a retrospective cross-sectional study of the medical records and scans of all patients according to the international classification of diseases-10 version (ICD-10) with M43.006 (spondylolisthesis) and M51.202 (lumbar disc herniation) from January 1, 2016, to June 30, 2020. According to the inclusion and exclusion criteria, 119 patients with isthmic spondylolisthesis (type II A) and 45 patients with degenerative spondylolisthesis at L5-S1 were enrolled in the IS group and DS group, respectively. One hundred and sixty-four cases of lumbar disc herniation without spondylolysis or spondylolisthesis were matched by the random number table method as the normal control (NL) group (Fig. 1). 
Dual-source spiral 64-slice CT scanner (SIMENS SOMATON, Germany) was used with the patients in supine position. Scanning parameters were $1 \mathrm{~mm}$ slice thickness / interval, with a pitch of 1.0-2.0. All raw data obtained from patients were stored in postprocessing workstation for reconstructions. Siemens Syngo software workstation was employed for random post-scanning imaging processing. Accuracy values of distance and angle measurements were $0.1 \mathrm{~mm}$ and $0.1^{\circ}$, respectively.

Measurements were performed in accordance with a previously published study by Olsewski et al. [9] and Vaccaro et al [10]. The following reference lines were drawn from the axial CT scans: a horizontal line along the transverse processes of the vertebra (a line), posterior margin tangent of the vertebral body ( $b$ line), a line perpendicular to the first reference line in the anteroposterior mid-line axis bisecting the vertebral body (c line), and a line drawn through the mid-axis of the pedicle and parallel to the pedicle (d line) (Fig. 2). This image, referred to as the mid-pedicle cut, was used to measure the transverse pedicle length (PL), pedicle width (PW), pedicle screw trajectory length (PSTL), and pedicle camber angle (PCA). And pedicle height (PH) was measured in sagittal CT reconstructive images (Fig. 3). The forward slip distance of the L5 vertebra was measured on an x-ray in the exact standing neutral lateral position, and the percentage of slip was defined as the ratio of the length between the posterior border of S1 to the perpendicular to posterior lower border of L5 over the entire length of S1 endplate according to the technique recommended by Bourassa-Moreau et al [11]. All of the parameters were performed twice by 2 attending physicians (observer 1: C.T. MD, observer 2: Y. L. MD) who were trained in spine surgery for more than 6 years, and the mean values of these obtained values were calculated for both right and left pedicles of the $L 5$ vertebra. The patients with spondylolisthesis were grouped by the Meyerding grade classification into grade 1 (G I), grade 2 (G II), grade 3 (G III), and grade 4 (G IV) in both the IS and DS groups. Height, weight, and body mass index (BMI) of all participants were recorded.

\section{Statistical analysis}

All statistical analyses were performed using SPSS statistical software version 19.0 (SPSS, Chicago, IL, USA). Independent ttests were used to determine the differences in pedicle parameters on the basis of sex (male or female) and side (left or right), and also to examine the differences in slip distance and percentage of slip between the IS and DS groups. An analysis of variance (ANOVA) was performed to check for significant differences among the IS, DS, and NL groups in all pedicle parameters and general information (age, height, weight, and BMI), and least significant difference (LSD) post-hoc analysis was used for all individual group comparisons. Pearson correlations were employed to examine all relationships between the pedicle parameters and the percentage of slip. The Chi-square test was used to compare categorical variables. Differences were considered statistically significant at $p<0.05$.

\section{Results}

The patient demographics in the three groups are noted in Table囚. The values of slip distance $(11.2 \pm 2.7 \mathrm{~mm})$ and percentage of slip $(29.1 \%$ $\pm 10.9 \%)$ in the IS group were larger than those in the DS group $(8.8 \pm 2.4 \mathrm{~mm}, 24.4 \% \pm 8.4 \%)(p<0.05)$. According to the Meyerding grade classification of spondylolisthesis, 46 patients were classified into grade 1 (G I), 67 patients into grade 2 (G II), and 6 patients into grade 3 (G III) in the IS group, and 27 patients into G I and 18 patients into G II in the DS group. There was no statistically significant difference among the IS, DS, and NL groups in height, weight, and BMI variables. Significant sex-related differences were observed in association with several parameters. But there were no significant differences between the right and left sides for any parameter in the IS, DS, and NL groups (Table II).

Difference in L5 pedicle parameters between the IS and DS groups based on the NL group

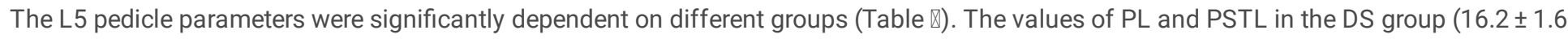
$\mathrm{mm}$ and $49.8 \pm 3.3 \mathrm{~mm}$ ) were significantly greater than those in the IS group $(14.4 \pm 2.1 \mathrm{~mm}$ and $48.3 \pm 4.2 \mathrm{~mm})$. On the contrary, the $P W$ and PCA in the DS group $\left(11.3 \pm 1.9 \mathrm{~mm}\right.$ and $\left.23.3^{\circ} \pm 6.5^{\circ}\right)$ were significantly smaller than those in IS group $\left(13.6 \pm 2.1 \mathrm{~mm}\right.$ and $\left.29.7^{\circ} \pm 5.3^{\circ}\right)$.

\section{Correlation between slippage and L5 pedicle parameters in the IS and DS groups}

In the IS group, no significant slippage-related difference was observed in association with the three parameters of the L5 pedicle according to the Meyerding grade classification, with PH and PW as sole exceptions (Fig. 4). The PH and PW in patients with a slip degree of G III (8.4 \pm $2.6 \mathrm{~mm}$ and $11.6 \pm 1.5 \mathrm{~mm}$ ) were significantly smaller than those in patients with a slip degree of $\mathrm{G} \mathrm{I}(9.8 \pm 1.4 \mathrm{~mm}$ and $13.6 \pm 1.8 \mathrm{~mm})$ and G II $(9.6 \pm 1.4 \mathrm{~mm}$ and $13.7 \pm 2.5 \mathrm{~mm})$. Pearson's correlation coefficients showed that there was no significant correlation between the percentage of slip and pedicle parameters.

In the DS group, the pedicle parameters were significantly different between G I and G II, with PH as the sole exception (Fig. 5). The PL and PSTL in patients with a slip degree of G I $(15.7 \pm 1.6 \mathrm{~mm}$ and $48.9 \pm 3.1 \mathrm{~mm})$ were significantly smaller than those in patients with a slip degree of G II (17.3 $\pm 1.1 \mathrm{~mm}$ and $51.6 \pm 2.9 \mathrm{~mm})$. On the contrary, the PW and PCA in patients with a slip degree of G I $(11.6 \pm 1.5 \mathrm{~mm}$ and

Page 3/13 
$\left.24.3^{\circ} \pm 6.8^{\circ}\right)$ were significantly greater than those in patients with a slip degree of $\mathrm{G} \mathrm{II}\left(10.4 \pm 1.2 \mathrm{~mm}\right.$ and $\left.21.2^{\circ} \pm 5.8^{\circ}\right)$. Furthermore, Pearson's correlation coefficients showed that the percentage of slip in the L5 vertebra was significantly positively correlated with PL ( $r=$ $0.640, p=0.0001)$, and it was negatively correlated with PW $(r=-0.510, p=0.0001)$ and PCA $(r=-0.405, p=0.006)$. There was a positive but not significant correlation between the percentage of slip and PSTL ( $r=0.274, p=0.071)$ (Fig. 6).

\section{Discussion}

Linear and angular measurements of the pedicle in the transverse and sagittal planes provide a quantitative description of the direction of pedicle screw insertion. However, the measurement results of L5 pedicle parameters in patients of the IS group were quite different in previous literary works. Bajwa et al. measured the L5 pedicle length of 1072 cadavers by one examiner and found an average increase of $29 \%$ in the pedicle length of spondylolysis specimens $(6.02 \mathrm{~mm}$ ) as compared with specimens from subjects without spondylolysis (4.31 mm) [5]. Choi et al. studied the CT scans of 70 patients with L5-S1 isthmic spondylolisthesis and concluded that the L5 pedicle had a significantly longer posterior compartment pedicle length (24.2 vs. $21.9 \mathrm{~mm})$, shorter width (10.8 $\mathrm{mm} \mathrm{vs.} 12 \mathrm{~mm})$, and lower height (11.2 vs. $12.4 \mathrm{~mm})$ than that in patients without spondylolisthesis [7]. In our study, the mean value of PL was $14.5 \mathrm{~mm}$, that of PSTL was $48.3 \mathrm{~mm}$, that of PW was $13.9 \mathrm{~mm}$, that of PH was $9.2 \mathrm{~mm}$, and that of PCA was $29.6^{\circ}$ in patients of the IS group. We identified smaller pedicle parameters of PL and $\mathrm{PH}$, but larger PW and PCA values in the IS group compared to the NL group. We deemed that different definitions of pedicle parameters were important factors, which led to differences between the results of this study and previous studies, in addition to the differences in measurement technique (CT or vernier caliper) and study population (cadavers or patients). Furthermore, we selected patients with type A isthmic spondylolisthesis that was defined a stress or fatigue fracture of the pars interarticularis by Wiltse [1] to avoid the false appearance of an increase in PL due to repeated isthmus healing and lengthening in type B.

We evaluated 45 patients in the DS group and found that the L5 pedicle had a significantly longer PL (16.2 vs. 15.4 mm), smaller PW (11.2 vs. $13.4 \mathrm{~mm})$ and PCA $\left(24.7^{\circ}\right.$ vs. $\left.27.0^{\circ}\right)$, and lower PH (9.6 vs. $\left.10.7 \mathrm{~mm}\right)$ than that in the NL group. This finding is consistent with the comparative results in previous literary works $[12,13]$. However, no study has reported the morphological difference in the $L 5$ pedicle between isthmic and degenerative spondylolisthesis at L5-S1. In our study, the PL and PSTL of the slip vertebra in patients with degenerative spondylolisthesis were significantly longer than those in patients with isthmic spondylolisthesis, but the PW and PCA were significantly smaller. We found that the L5 pedicle morphology in the IS group showed abduction, shortness, and width, while that in the DS group showed adduction, lengthening, and thinning compared with the NL group. Especially, the average value of PCA in DS group $\left(29.7^{\circ}\right)$ was 6.4 degrees smaller than that of IS group $\left(29.6^{\circ}\right)$. Yu et al. measured the safe range of transverse section angle of three common lumbar pedicle screw insertion points (Du, Magerl and Roy-Camille) in 40 adult volunteers by CT images. And they found that the safe range of transverse section angle measured by Du, Magerl and Roy-Camille's techniques at L5 were $10.48^{\circ} \pm 0.76^{\circ}, 14.13^{\circ} \pm 1.11^{\circ}$, and $4.13^{\circ} \pm 0.84^{\circ}$, respectively $[14]$. Therefore, paying attention to the difference of PCA between DS and IS group is particularly important for surgeons to avoid screw misplacement, if there is no navigation. Why is there a difference in the pedicle morphology between isthmic and degenerative spondylolisthesis?

The pathogenesis and natural history of isthmic and degenerative spondylolisthesis and the subsequent development mechanisms of vertebral slip are different. Isthmic spondylolisthesis has been defined as a condition in which "fibrous defects are present in the pars interarticularis that permit forward displacement of the upper vertebrae and separation of the anterior aspects of the vertebra from its neural arch" [15]. Approximately $15 \%$ of individuals with a pars interarticularis defect showed progression to spondylolisthesis. The slip was seen predominately during the growth spurt, with minimal change after the age of sixteen years. Although not clearly stated, there is an ample evidence in the literature to suggest that slippage, when it occurs, is usually demonstrable at about the same time when the pars interarticularis defect is first detected roentgenographically [15]. Slipping may also occur and (or) increase in the adult population related to disc degeneration at the slip level with a prevalence of 5.6-30\% [15-17]. However, unlike isthmic spondylolisthesis, degenerative spondylolisthesis is most common in the sixth decade of life, and the pathophysiology of this type of spondylolisthesis has been postulated to be a combination of disc and facet joint degeneration $[17,18]$. The natural history of degenerative spondylolisthesis was described by Matsunaga in 1990 in 145 conservatively treated patients with a minimum 10-year follow-up [18]. And slip progression in 49 patients (34\%) with the intervertebral disc height at the slip level decreased significantly throughout the follow-up. In addition, it has been reported that the sagittal balance of the spine plays a significant role in the development of DS and IS [19-24]. The basic concept of spinal compensation is the extension of the adjacent spinal segments to avoid the anterior translation of the gravity line due to progressive disc degeneration and loss of disc height [19]. This, however, causes adverse effects. In a retrospective study, Barrey et al. found that patients with DS have a higher pelvic incidence (PI) than a normal asymptomatic population [20]. Le and Barrey suggested that high PI appears to be a predictive factor of DS and may be involved in the onset and progression [21, 22]. Labelle et al. found PI to be significantly correlated with the degree of IS [23]. Rajnics et al. noted that the PI in IS populations was also significantly higher than in normal populations [24]. However, unlike DS, IS demonstrated a high lumbar lordosis (LL), a normal sacral slope (SS), a high pelvic tilt (PT), and the maintenance of a global sagittal balance within the normal range of sagittal vertical axis from C7 plumb line (SVA) [25]. 
Undoubtedly, preservation of most parts of the intervertebral disc as well as anatomical structure of the facet joint was considered to be attributable to maintenance of spinal stability. Although the mechanism is not yet clearly understood, research evidence suggests that it also acts as an essential reaction to prevent the slip progression of spondylolisthesis. Slip progression in spondylolysis is most likely to occur in adolescents younger than 15 years of age, usually during the adolescent growth spurt [26]. Vertebral slippage can be explained by the fact that the lumbosacral junction is subjected to considerable anterior shear forces [27]. A resilient intact disc acts as the main restraint against further slippage and keeps the spinal motion segment in a stable equilibrium [28]. It is postulated that slip progression after skeletal maturity is almost always related to disc degeneration at the slip level. As the biochemical and biomechanical integrity of the disc is lost, the lumbosacral slip becomes unstable and progresses. In adult isthmic spondylolisthesis, slip progression in these patients was uniformly accompanied by disc degeneration below the pars defect. As the disc degenerated, its capacity to resist the anterior shear forces was considerably diminished, leading to further slippage [28, 29]. However, for degenerative spondylolisthesis, the posterior intact facet joint may also play an important role in preventing the slip progression and maintaining the stability of the spine in addition to the intervertebral disc resisting part of anterior shear forces. Some studies have indicated a correlation between degenerative spondylolisthesis and morphological changes in the facet joint with more sagittal orientation in the axial plane and more horizontal orientation in the sagittal plane [30, 31]. But it is unclear whether the facet orientation is a primary cause or a secondary effect [32]. Cho et al. found that 29 (53.7\%) of 54 patients with degenerative spondylolisthesis had facet fluid on their MR images, and they considered that this was a phenomenon of facet cartilage degeneration caused by increased facet load because of intervertebral disc degeneration [33]. In addition, the degree of facet osteoarthritis with narrowing of the joint space, large osteophytes, and subchondral erosions was also greater in degenerative spondylolisthesis in previous studies [33,34]. The area of contact between the facet joints increases with facet hyperplasia, large osteophytes, and narrowed joint space, which increases the resilience of the facets with an increasing load bearing capacity to withstand the movements that occur in spondylolisthesis. Based on the above evidence, for the first time, we propose the hypothesis that facet cartilage degeneration with narrowing of the joint space, large osteophytes, and subchondral erosions at the slippage level, as a self-protection mechanism, is compensatory for the progression of degenerative spondylolisthesis to resist the anterior shear forces of the slippage vertebra.

Thus, the pedicle of sliding vertebrae, as the mechanical bridge connecting the vertebra and the vertebral arch, may undergo stress remodeling in the progression of degenerative spondylolisthesis. While slippage occurs, because there is an intact vertebral arch in the sliding vertebra, the pedicle is able to resist the shear forces of the forward sliding of the vertebra by the backward reverse stress from the facet joints. This reverse stress mainly included the following: 1) the backward and inward force of the superior articular process of the lower vertebra to the inferior articular process of the sliding vertebra; 2) the restrictive force of a hypertrophic osteophyte around the facet joints on the inferior articular process of the sliding vertebra. Therefore, due to the long-term abnormal stress traction, the adaptive remodeling of the pedicle of sliding vertebra showed an adduction, lengthening, and thinning morphological change (Fig. 7). In the present study, we confirmed that the pedicle parameters, such as PL, PSTL, PW, and PCA, in degenerative spondylolisthesis were significantly correlated with the degree of vertebral slip. The findings seem to support our view and hypothesis that the stress and adaptive remodeling of the pedicle of the sliding vertebra occurred during the progression of degenerative spondylolisthesis. Isthmic spondylolisthesis, however, had a pedicle morphological change of abduction, shortness, and width in our study. There was no correlation between the pedicle parameters and the degree of vertebral slip. Because of the incomplete vertebral arch ring due to the defect in the pars interarticularis, it can be inferred that the pedicle is hardly affected by the reverse stress during the progression of isthmic spondylolisthesis as a result of its separation from the vertebral arch ring. Thus, the phenomenon of pedicle stress remodeling is not obvious in the development of isthmic spondylolisthesis (Fig. 8).

Our study also has some limitations. First, as already known, degenerative spondylolisthesis most commonly occurs at the L4-5 level (6-9 times more common than that at the other levels). But the subjects included in our study had L5-S1 degenerative spondylolisthesis, and this is also the reason for the low number of cases. The purpose of this selection and design is to make it more objective and reasonable to compare with L5-S1 isthmic spondylolisthesis. Second, there are three subclasses of isthmic spondylolisthesis according to the classification of spondylosis modified by Wiltse [1]: A, which is due to a stress or fatigue fracture of the pars interarticularis; B, an elongation of the pars interarticularis; and $\mathrm{C}$, which is due to an acute fracture of the pars interarticularis. But only patients with type $\mathrm{A}$ isthmic spondylolisthesis were included in this study. Further research, particularly a prospective longitudinal cohort clinical study, is needed to verify our views and hypothesis.

\section{Conclusion}

The pedicles of the fifth lumbar vertebra were shorter and wider, and the PCA was larger in L5-S1 isthmic spondylolisthsis compared to the normal subjects. But the pedicles in degenerative spondylolisthsis were elongated and thinner, and the PCA was smaller compared to the normal subjects. The pedicle parameters of PL were significantly positively correlated with the percentage of slip in patients with degenerative spondylolisthsis, the PW and PCA were significantly negatively correlated with the percentage of slip. However, there was no correlation between the percentage of slip and L5 pedicle parameters in patients with isthmic spondylolisthsis. These findings suggest that the pedicle of sliding vertebrae in degenerative spondylolisthsis, as the mechanical bridge connecting the vertebra and the intact vertebral

Page 5/13 
arch, may undergo stress remodeling to support the changes in stress forces induced by the disc degeneration and facet arthritic changes in the progression of spondylolisthesis. Surgeons planning to perform fusion operations at L5-S1 spondylolisthesis should be careful in choosing the length, diameter of screws, and the insertion angle of the screws. The mid-pedicle transverse plane adjustment of CT imaging would be important preoperatively to avoid screw misplacement, if there is no navigation.

\section{Declarations}

Statements: The manuscript submitted does not contain information about medical device (s) /drug(s).

No funds were received in support of this work. All subjects gave informed consent to participate and that the study was approved by an institutional review board (No. KY2020155)

Acknowledgments $₫$ The authors would like to thank to all the patients of the Affiliated Hospital of Southwest Medical University for allowing to publish the paper and to use their images taken during hospital admission.

\section{Conflict of interest! None.}

\section{References}

1. Wiltse LL, Newman PH, MacNab I (1976) Classification of spondylolysis and spondylolisthesis. Clin Orthop Relat Res 117:23-29

2. Madan S, Boeree NR (2002) Outcome of posterior lumbar interbody fusion versus posterolateral fusion for spondylolytic spondylolisthesis. Spine (Phila Pa 1976) 27:1536-1542

3. Nojiri K, Matsumoto M, Chiba K, Toyama Y, Momoshima S (2005) Comparative assessment of pedicle morphology of the lumbar spine in various degenerative diseases. Surg Radiol Anat 27(4):317-321

4. Mehta JS, Kochhar S, Harding IJ (2012) A slip above a slip: retrolisthesis of the motion segment above a spondylolytic spondylolisthesis. Eur Spine J 21:2128-2133

5. Bajwa NS, Toy JO, Ahn NU (2012) L5 pedicle length is increased in subjects with spondylolysis: an anatomic study of 1072 cadavers. Clin Orthop Relat Res 470(11):3202-3206

6. Foreman P, Griessenauer CJ, Watanabe K, Conklin M, Shoja MM, Rozzelle CJ, Loukas M, Tubbs RS (2013) L5 spondylolysis/spondylolisthesis: a comprehensive review with an anatomic focus. Childs Nerv Syst 29(2):209-216

7. Choi HJ, Park JY, Chin DK, Kim KS, Cho YE, Kuh SU (2014) Anatomical parameters of fifth lumbar vertebra in L5-S1 spondylolytic spondylolisthesis from a surgical point of view. Eur Spine J 23(9):1896-1902

8. Abu-Leil S, Floman Y, Bronstein Y, Masharawi Y (2016) A morphometric analysis of all lumbar intervertebral discs and vertebral bodies in degenerative spondylolisthesis. Eur Spine J 25(8):2535-2545

9. Olsewski JM, Simmons EH, Kallen FC, Mendel FC, Severin CM, Berens DL (1990) Morphometry of the lumbar spine: anatomical perspectives related to transpedicular fixation. J Bone Joint Surg Am 72(4):541-549

10. Vaccaro AR, Rizzolo SJ, Allardyce TJ, Ramsey M, Salvo J, Balderston RA, Cotler JM (1995) Placement of pedicle screws in the thoracic spine. Part I: Morphometric analysis of the thoracic vertebrae. J Bone Joint Surg Am 77(8):1193-1199

11. Bourassa-Moreau E, Mac-Thiong J-M, Labelle H (2010) Redefining the technique for the radiologic 23 measurement of slip in spondylolisthesis. Spine (Phila Pa 1976) 35:1401-1405

12. Hou S, Hu R, Shi Y (1993) Pedicle morphology of the lower thoracic and lumbar spine in a Chinese population. Spine 18:1850-1855

13. Robertson PA, Novotny JE, Grobler LJ, Agbai JU (1998) Reliability of axial landmarks for pedicle screw placement in the lower lumbar spine. Spine 23:60-66

14. Hailong Y, Wei L, Zhensheng M, Hongxun S (2007) Computer analysis of the safety of using three different pedicular screw insertion points in the lumbar spine in the Chinese population. Eur Spine J 16(5):619-623

15. Fredrickson BE, Baker D, McHolick WJ, Yuan HA, Lubicky JP (1984) The natural history of spondylolysis and spondylolisthesis. J Bone Joint Surg Am 66(5):699-707

16. Kalichman L, Kim DH, Li L, Guermazi A, Berkin V, Hunter J (2009) Spondylolysis and spondylolisthesis: prevalence and association with low back pain in the adult community-based population. Spine 34:199-205

17. Love TW, Fagan AB, Fraser RD (1999) Degenerative spondylolisthesis: developmental or acquired? J Bone Joint Surg Br 81:670-674

18. Boden SD, Riew KD, Yamaguchi K, Branch TP, Schellinger D, Wiesel SW (1996) Orientation of the lumbar facet joints: association with degenerative disc disease. J Bone Joint Surg Am 78:403-411

Page 6/13 
19. Le Huec JC, Thompson W, Mohsinaly Y, Barrey C, Faundez A (2019) Sagittal balance of the spine. Eur Spine J 28(9):1889-1905

20. Barrey C, Jund J, Noseda O, Roussouly P (2007) Sagittal balance of the pelvis-spine complex and lumbar degenerative diseases. A comparative study about 85 cases. Eur Spine J 16:1459-1467

21. Barrey C, Jund J, Perrin G, Roussouly P (2007) Spinopelvic alignment of patients with degenerative spondylolisthesis. Neurosurgery 61:981-986

22. Le Huec JC, Faundez A, Dominguez D, Hoffmeyer P, Aunoble S (2015) Evidence showing the relationship between sagittal balance and clinical outcomes in surgical treatment of degenerative spinal diseases: a literature review. International orthopaedics 39(1):87-95

23. Labelle H, Roussouly P, Berthonnaud E, Transfeldt E, O’Brien M, Chopin D (2004) Spondylolisthesis, pelvic incidence, and spinopelvic balance: a correlation study. Spine (Phila Pa 1976) 29:2049-2054

24. Rajnics P, Templier A, Skalli W, Lavaste F, Illés T (2002) The association of sagittal spinal and pelvic parameters in asymptomatic persons and patients with isthmic spondylolisthesis. J Spinal Disord Tech 15:24-30

25. Lim JK, Kim SM (2013) Difference of Sagittal Spinopelvic Alignments between Degenerative Spondylolisthesis and Isthmic Spondylolisthesis. J Korean Neurosurg Soc 53(2):96-101

26. Seitsalo S, Osterman K, Hyvarinen H, Tallroth K, Schlenzka D, Poussa M (1991) Progression of spondylolisthesis in children and adolescents: A long-term follow-up of 272 patients. Spine 16:417-421

27. Troup JDG (1976) Mechanical factors in spondylolisthesis and spondylolysis. Clin Orthop 117:59-67

28. Floman Y (2000) Progression of lumbosacral isthmic spondylolisthesis in adults. Spine (Phila Pa 1976) 25(3):342-347

29. Beutler WJ, Fredrickson BE, Murtland A, Sweeney CA, Grant WD, Baker D (2003) The natural history of spondylolysis and spondylolisthesis. 45-year follow-up evaluation. Spine 28:1027-1035

30. Grobler LJ, Robertson PA, Novotny JE, Ahern JW (1993) Decompression for degenerative spondylolisthesis and spinal stenosis at L4-5. The effects on facet joint morphology. Spine 18:1475-1482

31. Morimoto M, Higashino K, Manabe H, Tezuka F, Yamashita K, Takata Y, Takao S, Sakai T, Chikawa T, Nagamachi A, Sairyo K (2019) Agerelated changes in axial and sagittal orientation of the facet joints: Comparison with changes in degenerative spondylolisthesis. $\mathrm{J}$ Orthop Sci 24(1):50-56

32. Love TW, Fagan AB, Fraser RD (1999) Degenerative spondylolisthesis: developmental or acquired? J Bone Joint Surg Br 81:670-674

33. Cho BY, Murovic JA, Park J (2009) Imaging correlation of the degree of degenerative L4-5 spondylolisthesis with the corresponding amount of facet fluid. J Neurosurg Spine 11(5):614-619

34. Kundakci YE, Unver Dogan N, Guler I, Uysal II, Fazliogullari Z, Karabulut AK (2018) Evaluation of the facet joints with magnetic resonance images in the patients with disc degeneration and spondylolisthesis. Surg Radiol Anat 40(9):1063-1075

\section{Tables}

\begin{tabular}{|c|c|c|c|c|}
\hline BLE 1 Del & Jate & jroups & & \\
\hline & IS Group & DS Group & NL Group & $\mathrm{P}$ value \\
\hline Age & $50.2 \pm 10.4$ & $62.3 \pm 7.8$ & $52.7 \pm 9.2$ & $<0.001$ \\
\hline Sex & & & & 0.453 \\
\hline Male & 47 & 13 & 60 & \\
\hline Female & 72 & 32 & 104 & \\
\hline Height $(\mathrm{cm})$ & $162.3 \pm 6.8$ & $158.7 \pm 6.4$ & $160.9 \pm 7.1$ & 0.108 \\
\hline Weight $(\mathrm{kg})$ & $60.1 \pm 8.0$ & $60.4 \pm 7.8$ & $61.3 \pm 8.5$ & 0.542 \\
\hline BMI $(\mathrm{kg} / \mathrm{m} 2)$ & $23.1 \pm 2.7$ & $24.0 \pm 2.8$ & $23.6 \pm 2.3$ & 0.142 \\
\hline Slip distance $(\mathrm{mm})$ & $11.2 \pm 2.7$ & $8.8 \pm 2.4$ & & 0.014 \\
\hline Percentage of slip (\%) & $29.1 \pm 10.9$ & $24.4 \pm 8.4$ & & 0.012 \\
\hline Meyerding grade & & & & 0.026 \\
\hline $\mathrm{G} \square$ & 46 & 27 & & \\
\hline $\mathrm{G} \square$ & 67 & 18 & & \\
\hline $\mathrm{G} \square$ & 6 & 0 & & \\
\hline $\mathrm{G}$ & 0 & 0 & & \\
\hline $\begin{array}{l}\text { IS isthm } \\
\text { NL lum }\end{array}$ & & & dylolith & \\
\hline
\end{tabular}


TABLE 0 Difference of L5 Pedicle Parameters in Sex and Sides

\begin{tabular}{|c|c|c|c|c|c|c|c|c|c|c|}
\hline \multirow{2}{*}{ Pedicle } & \multicolumn{2}{|c|}{$\mathrm{PL}(\mathrm{mm})$} & \multicolumn{2}{|c|}{ PSTL $(\mathrm{mm})$} & \multicolumn{2}{|c|}{ PW (mm) } & \multicolumn{2}{|c|}{$\mathrm{PH}(\mathrm{mm})$} & \multicolumn{2}{|c|}{$\mathrm{PCA}\left({ }^{\circ}\right)$} \\
\hline & Male & Female & Male & Female & Male & Female & Male & Female & Male & Female \\
\hline $\begin{array}{l}\text { IS } \\
\text { Group }\end{array}$ & & & & & & & & & & \\
\hline Left & $15.2 \pm 2.6^{*}$ & $13.8 \pm 1.6$ & $50.1 \pm 3.8^{*}$ & $47.0 \pm 3.9$ & $15.2 \pm 2.8^{*}$ & $13.1 \pm 1.8$ & $9.7 \pm 1.2$ & $9.2 \pm 1.6$ & $29.8 \pm 5.4$ & $29.7 \pm 5.6$ \\
\hline Right & $15.7 \pm 2.4^{*}$ & $14.0 \pm 1.9$ & $51.4 \pm 3.1 *$ & $47.3 \pm 4.1$ & $14.4 \pm 2.0 *$ & $12.9 \pm 1.9$ & $10.2 \pm 1.2$ & $9.7 \pm 1.6$ & $30.3 \pm 4.7$ & $29.4 \pm 5.4$ \\
\hline Total & $15.5 \pm 2.5^{*}$ & $13.9 \pm 1.7$ & $50.8 \pm 3.5^{*}$ & $47.2 \pm 4.0$ & $14.8 \pm 2.2^{*}$ & $13.0 \pm 1.9$ & $10.0 \pm 1.2$ & $9.4 \pm 1.6$ & $30.1 \pm 5.0$ & $29.5 \pm 5.5$ \\
\hline $\begin{array}{l}\text { DS } \\
\text { Group } \\
\end{array}$ & & & & & & & & & & \\
\hline Left & $16.3 \pm 1.8$ & $16.1 \pm 1.4$ & $49.6 \pm 3.6$ & $49.3 \pm 2.9$ & $11.7 \pm 1.8$ & $11.6 \pm 1.7$ & $10.9 \pm 2.2^{*}$ & $9.1 \pm 1.5$ & $23.1 \pm 5.4$ & $23.0 \pm 6.7$ \\
\hline Right & $16.2 \pm 1.5$ & $16.4 \pm 1.6$ & $50.2 \pm 3.8$ & $50.1 \pm 3.2$ & $11.1 \pm 1.4$ & $11.1 \pm 2.1$ & $10.6 \pm 1.4^{*}$ & $9.4 \pm 1.5$ & $22.7 \pm 4.2$ & $23.8 \pm 7.0$ \\
\hline Total & $16.3 \pm 1.6$ & $16.2 \pm 1.5$ & $49.9 \pm 3.7$ & $49.7 \pm 3.0$ & $11.4 \pm 1.6$ & $11.3 \pm 1.9$ & $10.8 \pm 1.8^{*}$ & $9.3 \pm 1.5$ & $22.9 \pm 4.7$ & $23.4 \pm 6.8$ \\
\hline $\begin{array}{l}\text { NL } \\
\text { Group }\end{array}$ & & & & & & & & & & \\
\hline Left & $15.5 \pm 1.7$ & $14.9 \pm 1.9$ & $50.0 \pm 3.1 *$ & $47.3 \pm 3.2$ & $13.9 \pm 1.8 *$ & $12.4 \pm 1.8$ & $11.2 \pm 1.5^{*}$ & $10.5 \pm 1.1$ & $27.2 \pm 4.7$ & $28.0 \pm 4.9$ \\
\hline Right & $15.5 \pm 1.4^{*}$ & $14.8 \pm 1.7$ & $50.2 \pm 3.1 *$ & $47.3 \pm 3.5$ & $13.4 \pm 1.7^{*}$ & $12.0 \pm 1.8$ & $11.3 \pm 1.4^{*}$ & $10.5 \pm 1.2$ & $26.4 \pm 4.3$ & $27.2 \pm 4.7$ \\
\hline Total & $15.5 \pm 1.5^{*}$ & $14.9 \pm 1.8$ & $50.1 \pm 3.1 *$ & $47.3 \pm 3.3$ & $13.7 \pm 1.8 *$ & $12.2 \pm 1.8$ & $11.3 \pm 1.4^{*}$ & $10.5 \pm 1.1$ & $26.8 \pm 4.5$ & $27.6 \pm 4.8$ \\
\hline
\end{tabular}

\begin{tabular}{|c|c|c|c|c|}
\hline & NL Group & IS Group & DS Group & P value \\
\hline PL (mm) & $15.1 \pm 1.7$ & $14.4 \pm 2.1$ & $16.2 \pm 1.6$ & $<0.001^{*}$ \\
\hline PSTL (mm) & $48.5 \pm 3.5$ & $48.3 \pm 4.2$ & $49.8 \pm 3.3$ & $<0.05^{\#}$ \\
\hline PW (mm) & $12.7 \pm 1.9$ & $13.6 \pm 2.1$ & $11.3 \pm 1.9$ & $<0.001^{*}$ \\
\hline $\mathrm{PH}(\mathrm{mm})$ & $10.8 \pm 1.3$ & $9.6 \pm 1.5$ & $9.7 \pm 1.7$ & $<0.001^{9}$ \\
\hline $\mathrm{PCA}\left({ }^{\circ}\right)$ & $27.3 \pm 4.7$ & $29.7 \pm 5.3$ & $23.3 \pm 6.5$ & $<0.001^{*}$ \\
\hline \multicolumn{5}{|c|}{$\begin{array}{l}\text { IS isthmic spondylolisthesis; } \boldsymbol{D S} \text { degenerative spondylolisthesis; } \boldsymbol{N L} \text { lumbar disc herniation patients as normal population; } P L \text { pedicle length; PSTL pedicle } \\
\text { screw trajectory length; } \boldsymbol{P W} \text { pedicle width; } \boldsymbol{P H} \text { pedicle height; } \boldsymbol{P C A} \text { pedicle camber angle } \\
{ }^{*} \text { Post-hoc analysis revealed that there were significant differences among the three groups } \\
\text { \# Post-hoc analysis revealed that the PSTL in DS group was significantly higher than that in NL and IS group } \\
\text { I Post-hoc analysis revealed that the PH in NL group was significantly higher than that in DS and IS group }\end{array}$} \\
\hline
\end{tabular}

\section{Figures}




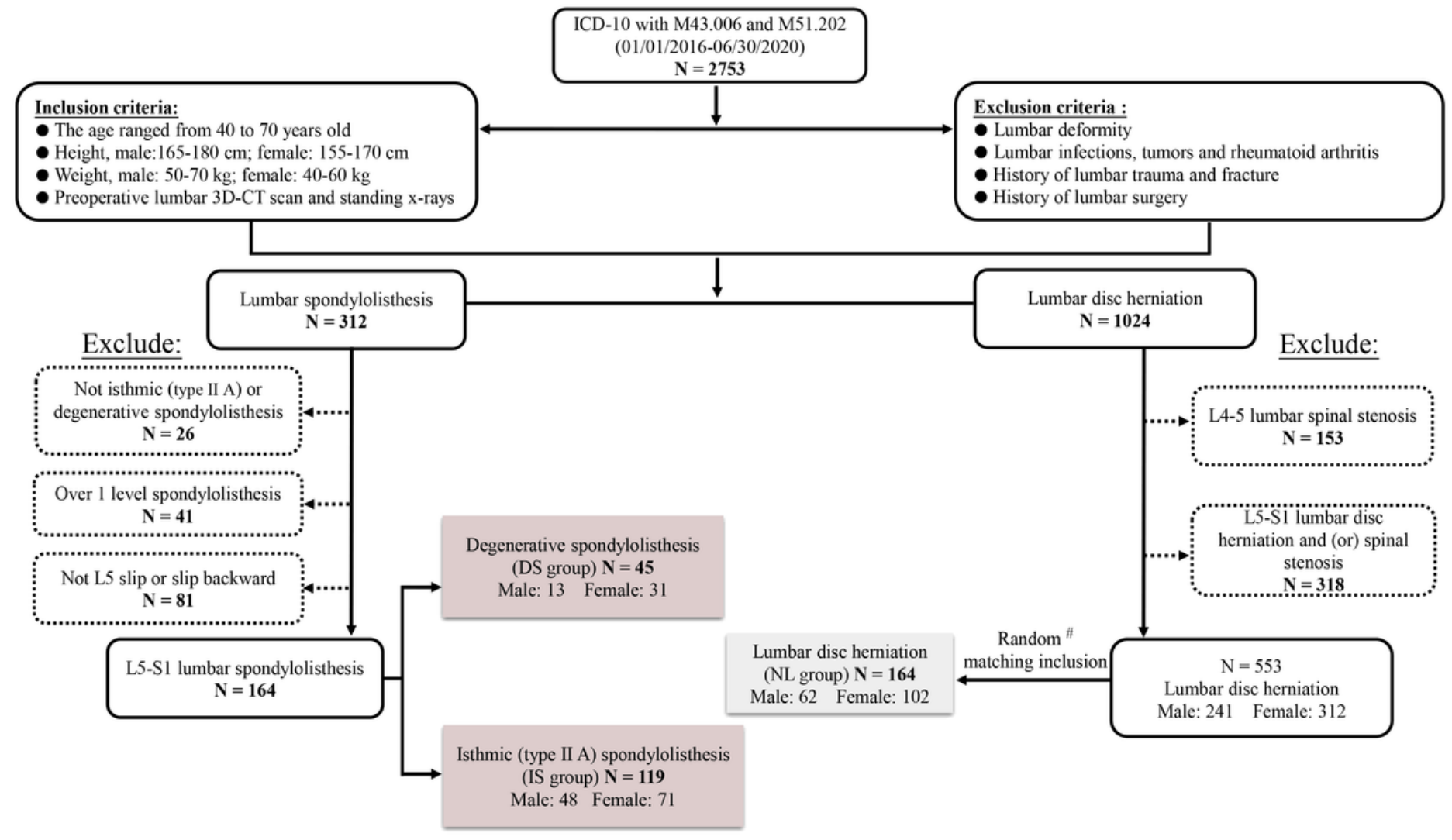

\section{Figure 1}

Flow chart demonstrating the inclusion results of research subjects. ICD-10, International classification of diseases-10 version. M43.006 = spondylolisthesis, M51.202 = lumbar disc herniation. \# All participants were classified by gender, and 62 males and 102 females were randomly selected by computer-generated random number table.
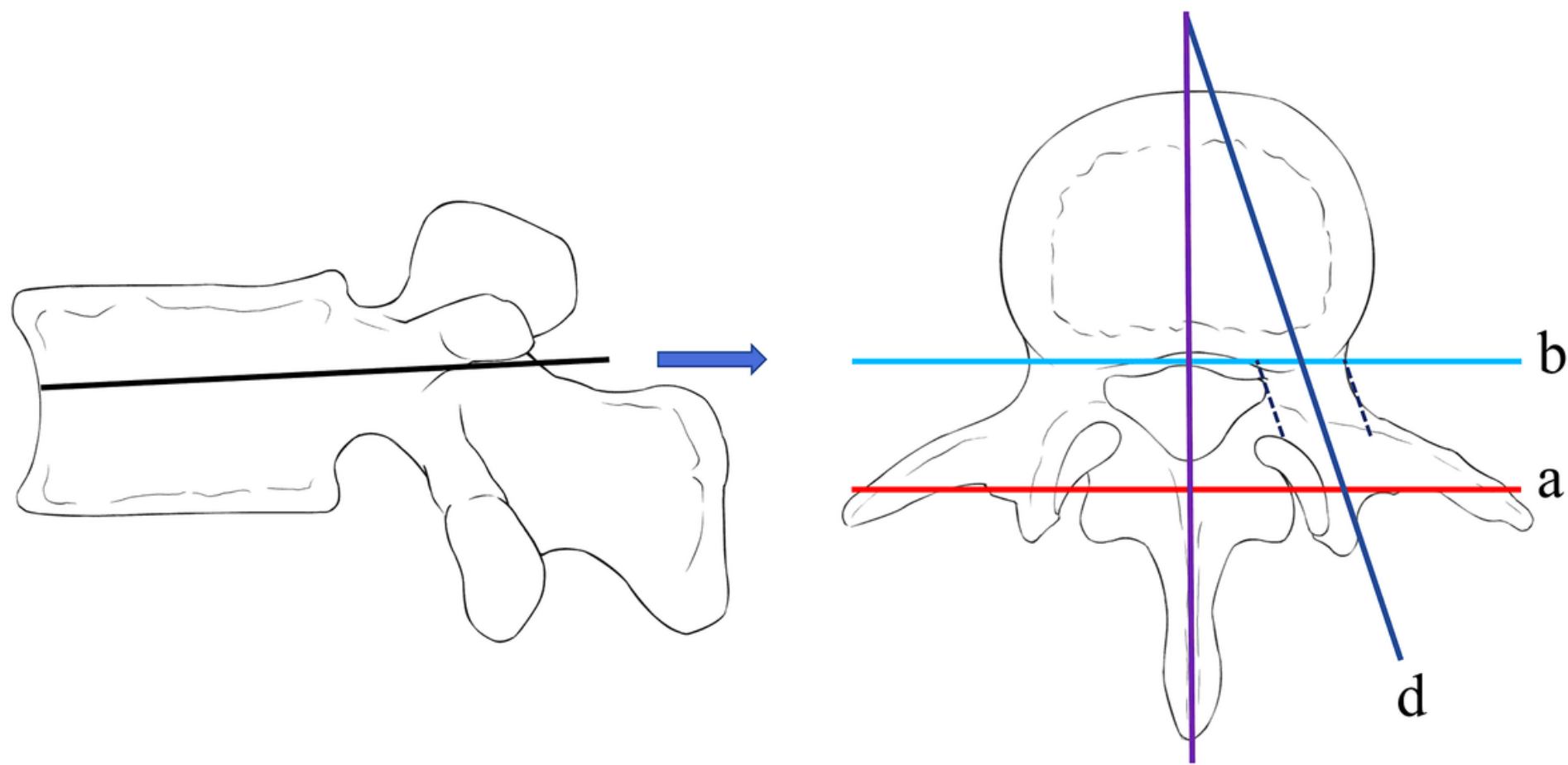

C 
Diagram of mid-pedicle axial section showing the reference lines. Inter-transverse line (a): a horizontal line along the transverse processes of the vertebra, posterior margin tangent line of the vertebral body(b), anteroposterior mid-sagittal line (c): a line perpendicular to the first reference line in the anteroposterior mid-line axis bisecting the vertebral body, and longitudinal pedicle axis line (d): a line drawn through the mid-axis of the pedicle and parallel to the pedicle

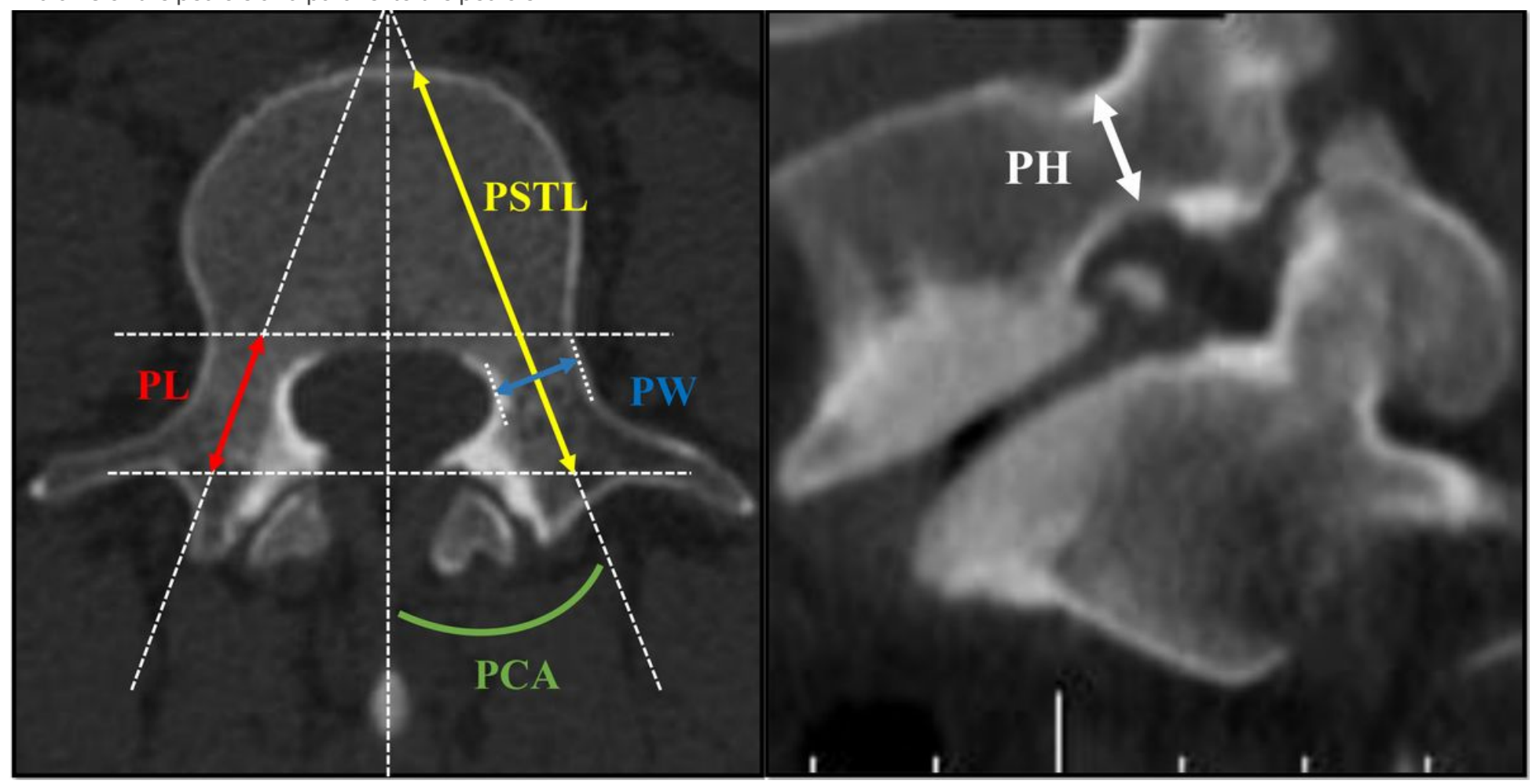

\section{Figure 3}

Diagram and axial CT scan at the mid-pedicle cut showing measurement of pedicle parameters. A, pedicle length $(\mathrm{PL})$ was measured from the inter-transvers line to the posterior margin tangent line of the vertebral body in the longitudinal pedicle axis line (red arrow), pedicle width (PW) was measured perpendicular to the longitudinal axis of the pedicle at the narrowest part (blue arrow), pedicle screw trajectory length (PSTL) was measured from the inter-transvers line to the anterior cortex of the vertebral body in the longitudinal pedicle axis line (yellow arrow), pedicle camber angle (PCA) was measured between the longitudinal pedicle axis and mid-sagittal line (green arc). B, pedicle height $\mathrm{PH})$ was measured in the sagittal plane at the middle of the pedicle width and was defined as the distance between its superior and inferior cortices (white arrow) 


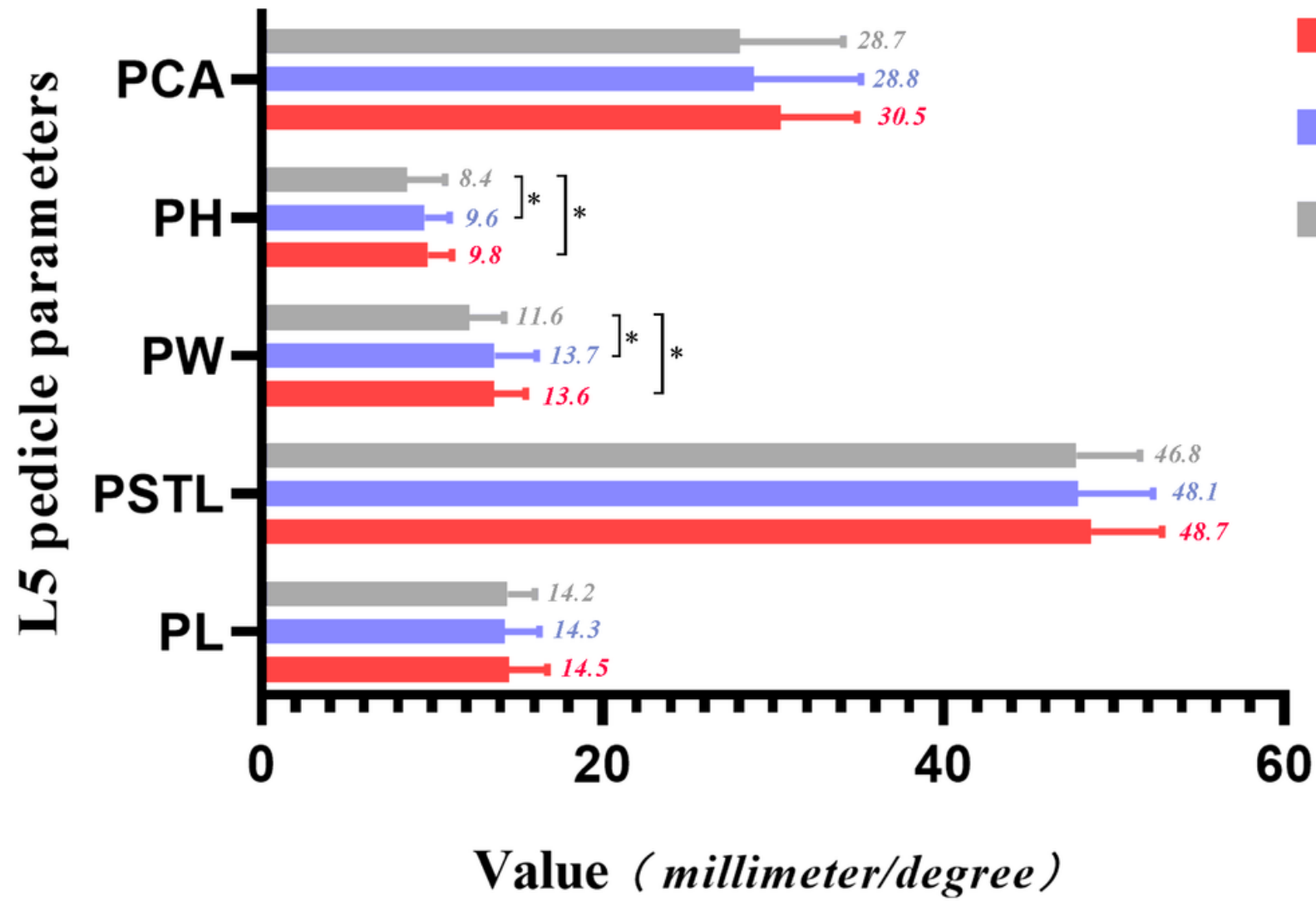

Figure 4

The comparation of L5 pedicle parameters according to the Meyerding grade classification in IS group. * $\mathrm{P}$ value $<0.05$

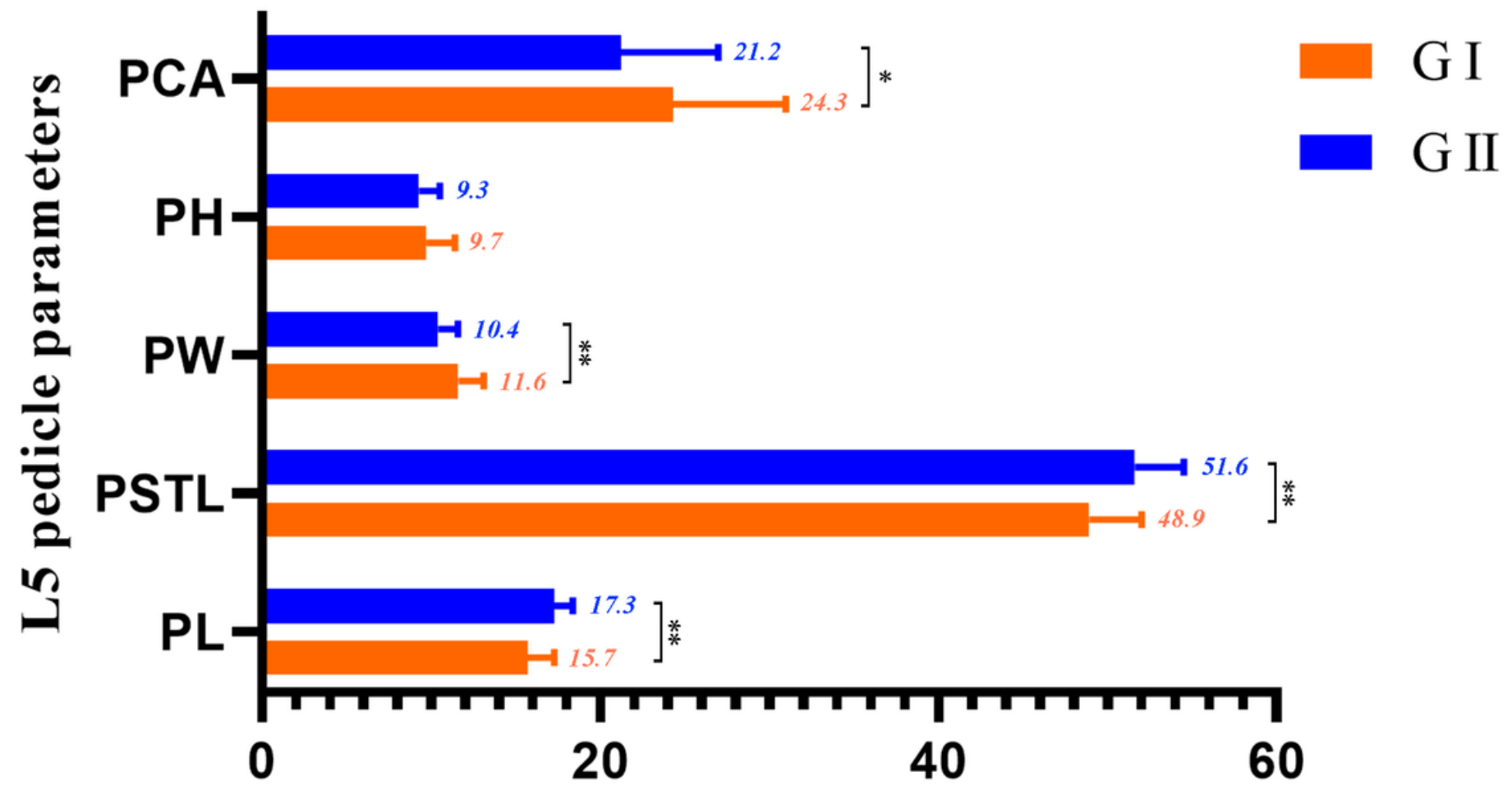

Value (millimeter/degree) 
Figure 5

The comparation of L5 pedicle parameters according to the Meyerding grade classification in DS group. * $P$ value $<0.05, \star \star P$ value $<0.001$
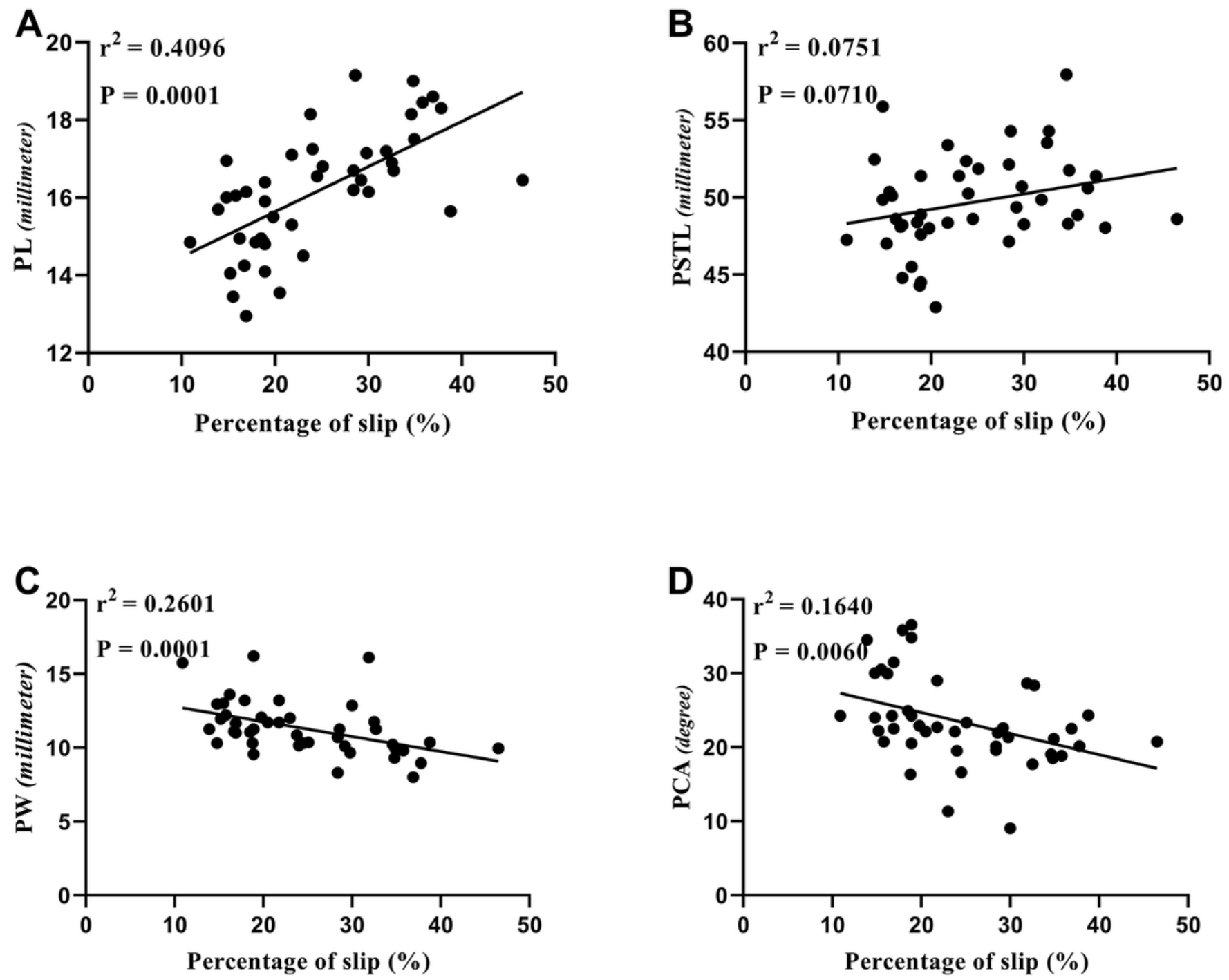

Figure 6

The correlation between slippage and L5 pedicle parameters in DS group. The percentage of slip in the L5 vertebra was significantly positively correlated with PL (A), and negatively correlated with PW (C) and PCA (D). There was a positive but not significant correlation between the percentage of slip and PSTL (B)

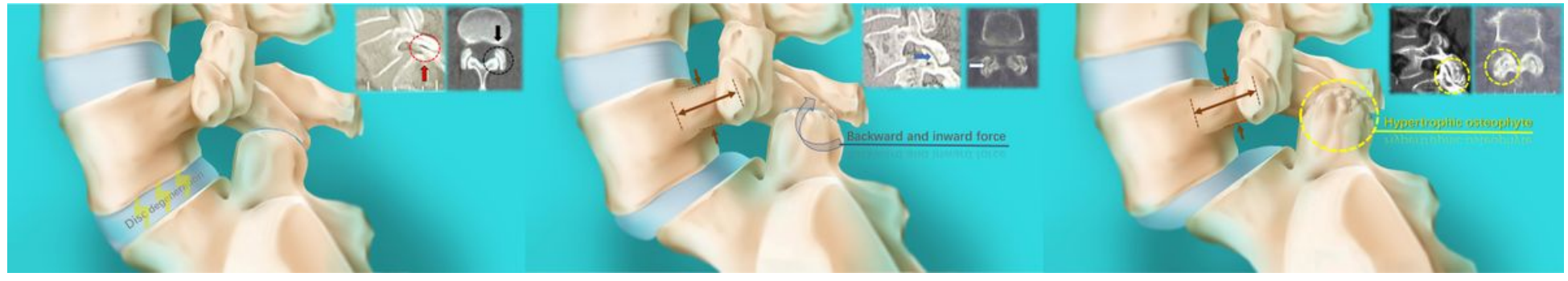

Figure 7

7 Illustration demonstrating that the stress and adaptive remodeling of the pedicle in the progression of degenerative spondylolisthesis. The etiology of degenerative spondylolisthesis was considered to be a combination of disc degeneration and facet joints morphological changes (Left panel: Fig. 7-A) with more sagittal orientation in the axial plane (black arrow) and more horizontal orientation in the sagittal plane (red 
arrow). The backward (blue arrow) and inward (white arrow) force of the superior articular process of the lower vertebra to the inferior articular progress of the sliding vertebra during the progression of degenerative spondylolisthesis, and the pedicle of sliding vertebra showed a stress remodeling with an adduction, lengthening, and thinning morphological change (Middle panel: Fig. 7-B). The hypertrophic osteophyte around the facet joints (yellow circle) enhances the restrictive force to the pedicle when the slip degree is further aggravated, and the stress remodeling effect of pedicle is further strengthened (Right panel: Fig. 7-C)

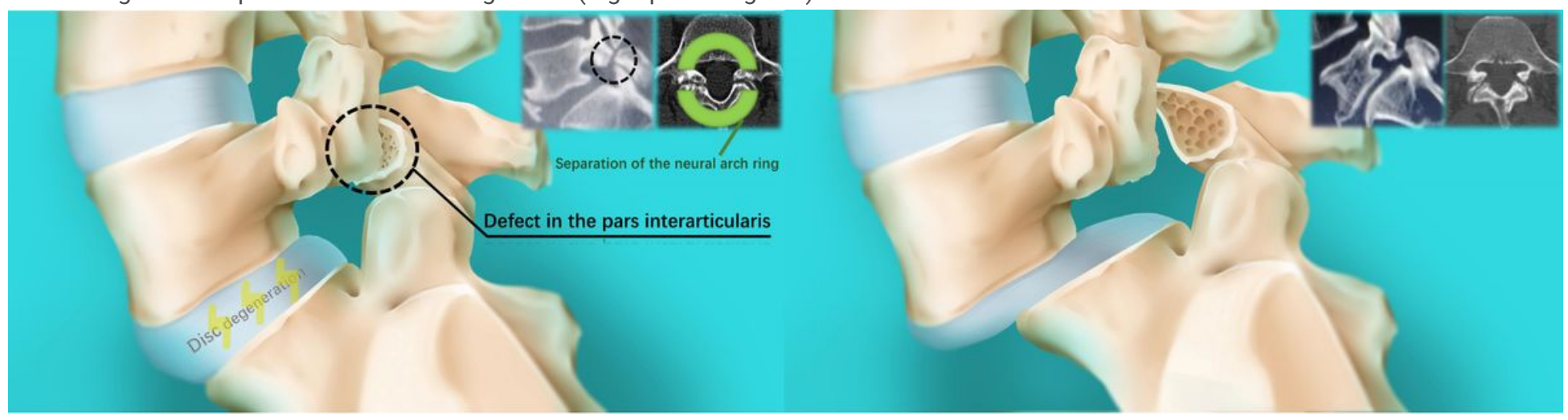

\section{Figure 8}

Illustration demonstrating that the pedicle morphological change in the progression of isthmic spondylolisthesis. The etiology of isthmic spondylolisthesis was considered to be a condition in which fibrous defects in the pars interarticularis (black circle) that permit forward displacement of the upper vertebrae and separation of the anterior aspects of the vertebra from its neural arch ring (Left panel: Fig. 8-A). The pedicle is hardly affected by the reverse stress during the progression of isthmic spondylolisthesis as a result of its separation from the vertebral arch ring, the phenomenon of pedicle stress remodeling is not obvious (Right panel: Fig. 8-B). 